\title{
The social context of food insecurity among persons living with HIV/AIDS in rural Uganda
}

\author{
Alexander C. Tsai ${ }^{1}$, David R. Bangsberg ${ }^{2,3,4,5,6,7}$, Nneka Emenyonu ${ }^{8}$, Jude K. Senkungu ${ }^{5}$, \\ Jeffrey N. Martin ${ }^{9}$, and Sheri D. Weiser ${ }^{10}$
}

${ }^{1}$ Robert Wood Johnson Health and Society Scholars Program, Harvard University, Cambridge, Massachusetts, United States ${ }^{2}$ Harvard Medical School, Boston, Massachusetts, United States ${ }^{3}$ Harvard Initiative for Global Health, Cambridge, Massachusetts, United States ${ }^{4}$ Center for Global Health, Massachusetts General Hospital, Boston, Massachusetts, United States ${ }^{5}$ Mbarara University of Science and Technology, Mbarara, Uganda ${ }^{6}$ Phillip T. and Susan M. Ragon Institute of Massachusetts General Hospital, Massachusetts Institute of Technology, and Harvard University; Charlestown, Massachusetts, United States ${ }^{7}$ Division of Global Health Equity, Brigham and Women's Hospital, Boston, Massachusetts, United States ${ }^{8}$ Department of Health Policy and Management, School of Public Health, University of North Carolina at Chapel Hill, Chapel Hill, North Carolina, United States ${ }^{9}$ Department of Epidemiology and Biostatistics, University of California at San Francisco, San Francisco, California, United States ${ }^{10}$ Division of HIV/AIDS and Center for AIDS Prevention Studies, University of California at San Francisco, San Francisco, California, United States

\section{Abstract}

HIV/AIDS and food insecurity are two of the leading causes of morbidity and mortality in subSaharan Africa, with each heightening the vulnerability to, and worsening the severity of, the other. Less research has focused on the social determinants of food insecurity in resource-limited settings, including social support and HIV-related stigma. In this study, we analyzed data from a cohort of 456 persons from the Uganda AIDS Rural Treatment Outcomes study, an ongoing prospective cohort of persons living with HIV/AIDS (PLWHA) initiating HIV antiretroviral therapy in Mbarara, Uganda. Quarterly data were collected by structured interviews. The primary outcome, food insecurity, was measured with the Household Food Insecurity Access Scale. Key covariates of interest included social support, internalized HIV-related stigma, HIV-related enacted stigma, and disclosure of HIV serostatus. Severe food insecurity was highly prevalent overall (38\%) and more prevalent among women than among men. Social support, HIV disclosure, and internalized HIV-related stigma were associated with food insecurity; these associations persisted after adjusting for household wealth, employment status, and other previously identified correlates of food insecurity. The adverse effects of internalized stigma persisted in a lagged specification, and the beneficial effect of social support further persisted after the inclusion of fixed effects. International organizations have increasingly advocated for addressing food insecurity as part of HIV/AIDS programming to improve morbidity and mortality. This study provides quantitative evidence on social determinants of food insecurity among

(C) 2011 Elsevier Ltd. All rights reserved.

Correspondence to: Alexander Tsai, MD, PhD, Harvard Center for Population and Development Studies, 9 Bow Street, Cambridge, MA 02138, United States. atsai@hsph.harvard.edu.

Publisher's Disclaimer: This is a PDF file of an unedited manuscript that has been accepted for publication. As a service to our customers we are providing this early version of the manuscript. The manuscript will undergo copyediting, typesetting, and review of the resulting proof before it is published in its final citable form. Please note that during the production process errors may be discovered which could affect the content, and all legal disclaimers that apply to the journal pertain. 
PLWHA in resource-limited settings and suggests points of intervention. These findings also indicate that structural interventions to improve social support and/or decrease HIV-related stigma may also improve the food security of PLWHA.

\section{Keywords}

Uganda; HIV/AIDS; international health; social support; stigma; food security

\section{INTRODUCTION}

HIV/AIDS and food insecurity contribute substantially to morbidity and mortality in subSaharan Africa (Masanjala, 2007). There are an estimated 33 million people living with HIV/AIDS (PLWHA) worldwide (UNAIDS, 2010), and in Uganda the prevalence of HIV among adults is approximately six percent (Uganda Ministry of Health, 2006). Food insecurity, defined as having uncertain or limited availability of nutritionally adequate food, or as being unable to procure food in socially acceptable ways (Anderson, 1990; Radimer, Olson, Greene, Campbell, \& Habicht, 1992) is also highly prevalent in resource-limited settings. In 2010, 239 million persons in sub-Saharan Africa were classified as undernourished (FAO, 2010). Nationwide estimates of the prevalence of food insecurity in Uganda are not available, but household surveys suggest it is widespread (Bukusuba, Kikafunda, \& Whitehead, 2007).

Both HIV/AIDS and food insecurity are intertwined in a vicious cycle, with each heightening the vulnerability to, and worsening the severity of, the other (S. D. Weiser, Young, Cohen, Kushel, Tsai, Tien et al., 2011b). HIV/AIDS affects food insecurity primarily through its corrosive effects on household economic viability, given the loss of wages when a family member's disease course worsens and the high price of funeral ceremonies for family members who have died as a result of the disease (Chapoto \& Jayne, 2008; Hosegood, Preston-Whyte, Busza, Moitse, \& Timaeus, 2007; Yamano \& Jayne, 2004). Poverty has been consistently recognized as a risk factor for food insecurity (Alaimo, Briefel, Frongillo, \& Olson, 1998; Lee \& Frongillo, 2001; Maes, Hadley, Tesfaye, \& Shifferaw, 2010; Nelson, Brown, \& Lurie, 1998; Normen, Chan, Braitstein, Anema, Bondy, Montaner et al., 2005; D. Rose, 1999a). In turn, food insecurity is recognized as a key determinant of reduced adherence to HIV antiretroviral therapy (ART) (S. Weiser, Wolfe, Bangsberg, Thior, Gilbert, Makhema et al., 2003; S. D. Weiser, Tuller, Frongillo, Senkungu, Mukiibi, \& Bangsberg, 2010) and a range of adverse health outcomes, including declines in physical health status (S. D. Weiser, Bangsberg, Kegeles, Ragland, Kushel, \& Frongillo, 2009a; S. D. Weiser, Tsai, Gupta, Frongillo, Kawuma, Senkungu et al., 2011a), decreased viral suppression (S. D. Weiser, Frongillo, Ragland, Hogg, Riley, \& Bangsberg, 2009c), worsened immunologic status (S. D. Weiser et al., 2009a), increased incidence of serious illness (S. D. Weiser et al., 2011a), and increased mortality (S. D. Weiser, Fernandes, Brandson, Lima, Anema, Bangsberg et al., 2009b).

Because of the myriad ways in which food insecurity can compromise the effectiveness of HIV treatment and care programs in resource-limited settings, international policymakers such as the World Food Programme (WFP) have emphasized the importance of understanding the determinants of food insecurity in order to appropriately integrate food insecurity interventions into HIV/AIDS programming (World Food Programme, 2003). Yet policymakers and programmers have received little guidance from the published literature. With few exceptions (Hadley, Mulder, \& Fitzherbert, 2007; Maes et al., 2010), most of the data on the determinants of food insecurity have been derived from resource-rich settings (Alaimo et al., 1998; Dean \& Sharkey, 2011; Heflin, Corcoran, \& Siefert, 2007; Lee \& 
Frongillo, 2001; Nelson et al., 1998; D. Rose, 1999a). Only four cross-sectional studies have examined determinants of food insecurity among PLWHA in the U.S. (Vogenthaler, Hadley, Lewis, Rodriguez, Metsch, \& del Rio, 2010; S. D. Weiser et al., 2009a) and Canada (Anema, Weiser, Fernandes, Ding, Brandson, Palmer et al., 2011; Normen et al., 2005). Our literature review revealed no published studies to date that have examined determinants of food insecurity among PLWHA in resource-limited settings.

\section{Conceptual Framework: Social Support, HIV Stigma, and Food Insecurity}

Because food procurement is fundamentally a social process in many resource-limited settings (Okoror, Airhihenbuwa, Zungu, Makofani, Brown, \& Iwelunmor, 2007), interventions targeting social support and HIV-related stigma may have beneficial effects on food insecurity. However, there is little research examining the effects of social support and HIV-related stigma on the experience of food insecurity among PLWHA in any setting. For most persons, food availability is determined by household resources and/or food production (Campbell, 1991; S. D. Weiser et al., 2011b) or, when these are insufficient to meet demand, government and private food aid (Campbell, 1991). Altruistic and transactional exchanges within the family and other social networks may be of immense importance in resourcelimited settings where formal safety nets provide inadequate insurance against health, agricultural, or income shocks (Carter \& Maluccio, 2003; de Weerdt \& Dercon, 2006; la Ferrara, 2003). Social support is conceptualized as the emotional, financial, or instrumental benefits derived from social networks (Berkman, 1984; Broadhead, Kaplan, James, Wagner, Schoenbach, Grimson et al., 1983). Coping strategies that draw on social supports may include sharing meals, borrowing money, and obtaining direct food assistance (Heumann, 2010; Kaschula, 2011; Ware, Idoko, Kaaya, Biraro, Wyatt, Agbaji et al., 2009). Correspondingly, in resource-rich settings, food insecurity has been found to be correlated with social isolation (Lee \& Frongillo, 2001) and inversely correlated with social support (Garasky, Morton, \& Greder, 2006). One cross-sectional analysis of data from rural Tanzania has shown that greater instrumental social support was positively correlated with food security (Hadley et al., 2007).

PLWHA may face additional barriers to achieving food security due to HIV-related stigma. Although greater availability of ART has attenuated the fear and uncertainty surrounding HIV/AIDS (Abadia-Barrero \& Castro, 2006; W. R. Wolfe, Weiser, Leiter, Steward, Percyde Korte, Phaladze et al., 2008), stigmatizing attitudes and beliefs about HIV/AIDS nonetheless remain widely held in resource-limited settings (Genberg, Hlavka, Konda, Maman, Chariyalertsak, Chingono et al., 2009; Simbayi, Kalichman, Strebel, Cloete, Henda, \& Mqeketo, 2007; W.R. Wolfe, Weiser, Bangsberg, Thior, Makhema, Dickinson et al., 2006). Enacted stigma, which is conceptualized as overt actions of discrimination and hostility directed towards PLWHA whose serostatus has been disclosed (Steward, Herek, Ramakrishna, Bharat, Chandy, Wrubel et al., 2008), may cause PLWHA to suffer discrimination-related job loss (W.R. Wolfe et al., 2006), experience erosion in their social support networks (Danziger, 1994; S.C. Kalichman, Simbayi, Cloete, Mthembu, Mkhonta, \& Ginindza, 2009; Mak, Cheung, Law, Woo, Li, \& Chung, 2007), be barred from purchasing food in the marketplace (Daniel, 1991), or have difficulties selling goods to wary non-infected persons (McGrath, Ankrah, Schumann, Nkumbi, \& Lubega, 1993; Muyinda, Seeley, Pickering, \& Barton, 1997). Consistent with these reports, in the 2004-05 Uganda HIV/AIDS Sero-Behavioural Survey, 29 percent of men and 41 percent of women reported that they would not buy sugar or fresh vegetables from a market vendor with HIV (Uganda Ministry of Health, 2006). Qualitative research from South Africa has also described difficulties faced by PLWHA in securing social transfers of food from neighbors (Kaschula, 2009). Taken together, these multiple lines of evidence suggest that serostatus disclosure, HIV-related stigma, and the erosion of social support may compromise the ability of 
PLWHA to secure food for their households. However, this has been the subject of little empirical research. We therefore undertook a study to understand the correlates of food insecurity among PLWHA in rural Uganda, with a specific focus on the associations with social support, HIV-related stigma, and HIV serostatus disclosure.

\section{METHODS}

\section{Participants and Setting}

Mbarara District (population 427,000) is located in a rural area of Uganda, 275 kilometers southwest of Kampala, or approximately five hours' driving by automobile. The local economy is largely based on subsistence agriculture. The town of Mbarara (population $82,000)$ is the primary commercial hub, but the majority of residents of the district $(92 \%)$ live in outlying rural areas. The majority of the population is ethnically Ankole, and the main local language is Runyankole. HIV prevalence in southwest Uganda is approximately 6\% (Uganda Ministry of Health, 2006). The Mbarara Regional Referral Hospital Immune Suppression Syndrome (ISS) Clinic dispenses free ART for PLWHA throughout southwestern Uganda and parts of Rwanda and the Democratic Republic of the Congo (Geng, Bwana, Kabakyenga, Muyindike, Emenyonu, Musinguzi et al., 2010).

Data for the analyses presented in this paper were drawn from the Uganda AIDS Rural Treatment Outcomes (UARTO) study. The UARTO study recruited patients from the ISS Clinic who were initiating ART. All ART-naïve patients above 18 years of age who were initiating free ART and who lived within 20 kilometers of the ISS Clinic were eligible to participate. Written consent was obtained from all study participants. In the event that there were cultural literacy reasons why a signature was not appropriate, participants were allowed to mark consent forms with an " $X$ ". Study participants were interviewed every three months by a research assistant who spoke the local language (Runyankole). Survey questions were translated into Runyankole, back-translated into English to ensure accuracy of interpretation, further modified through focus groups with key informants, and then pilottested to ensure clarity and relevance. Although the UARTO study was initiated in 2005, the questions on food security, HIV-related stigma, and social support were not added to the questionnaire until 2007. Therefore the data for these analyses are based only on data from 2007 onwards. All study interviews, which take approximately one hour to complete, took place in a private room at the site research office, which is located adjacent to the ISS Clinic. Ethical approval for all study procedures was obtained by the Committee on Human Research, University of California at San Francisco; the Partners Human Research Committee at Massachusetts General Hospital; the Institutional Ethical Review Committee, Mbarara University; and the Uganda National Council of Science and Technology.

\section{Measurement of Key Covariates}

The dependent variable of interest was food insecurity, measured using the Household Food Insecurity Access Scale (HFIAS) (Coates, Swindale, \& Bilinsky, 2006). Higher scores indicate more severe food insecurity, and the scores can also be used to assign households and populations to categories of severity ranging from food secure, mildly food insecure, moderately food insecure, to severely food insecure. At baseline, the Cronbach's alpha was 0.91 , indicating a high degree of internal consistency. In order to appropriately manage study participants' potential expectations about food aid and to minimize the risk of upwardly-biased scoring, research assistants explicitly informed participants that food would not be distributed during or after the study. The HFIAS was administered at baseline (i.e., when the food insecurity sub-study was initiated) and at each quarterly follow-up interview. (Details on the HFIAS and the other scales described in this section are set out in the Electronic Appendix available only with the online version of the paper.) 
Based on our review of the literature, we hypothesized that the following variables would affect food insecurity: HIV serostatus disclosure, social support, and HIV-related stigma. These variables, assessed at baseline and at each quarterly follow-up interview, were measured using a mix of single questions and multiple-item scales. Disclosure status was measured by a single binary variable indicating whether or not the study participant had disclosed her HIV status to a neighbor within the past three months. The survey instrument also inquired about disclosure to family members, but nearly all participants had disclosed to a family member at baseline. Because this did not provide sufficient variation to assess correlation with the outcomes of interest, we used the disclosure to neighbor variable instead. To measure social support, we used the Functional Social Support Scale (Antelman, Smith Fawzi, Kaaya, Mbwambo, Msamanga, Hunter et al., 2001), a modified version of the Duke University-University of North Carolina Functional Support Questionnaire (Broadhead, Gehlbach, de Gruy, \& Kaplan, 1988) consisting of questions related to perceived emotional and instrumental support. Higher scores reflected higher levels of social support. At baseline, the Cronbach's alpha was 0.91, indicating a high degree of internal consistency.

We used two different variables for enacted and internalized stigma. Internalized stigma refers to the extent to which PLWHA accept their discredited status as valid and develop self-defacing internal representations of themselves as PLWHA, whereas enacted stigma refers to overt acts of discrimination directed towards PLWHA because of his or her perceived stigmatized status (Steward et al., 2008). To measure internalized stigma, we used the Internalized AIDS-Related Stigma Scale (S.C. Kalichman et al., 2009). Higher scores indicate a greater degree of internalized stigma. At baseline, the Cronbach's alpha was 0.73, indicating an acceptable degree of internal consistency (and similar to the reliability scores obtained in the original validation study (S.C. Kalichman et al., 2009)). To measure enacted stigma, we developed a scale consisting of 13 items asking participants about whether they had ever (at baseline) or within the past three months (at baseline and at each quarterly follow-up interview) experienced various discriminatory events, such as abandonment, housing or property loss, or physical violence (Nyblade \& MacQuarrie, 2006). The enacted stigma scale was calculated as the total sum of the 13 items, with each item scored on a binary yes/no scale. The maximum score was 13 , with higher scores indicating greater degrees of enacted stigma experienced by the study participant. At baseline, the Cronbach's alpha was 0.72 , similar to the reliability of the internalized stigma scale.

\section{Other Demographic and Clinical Covariates}

In the multivariable regression models detailed below, we adjusted for other baseline (timeinvariant) covariates identified in prior work as potentially important correlates of food insecurity, i.e., "anything that limits either the household resources (money, time, information, health, etc.) or the proportion of those resources available for food acquisition" (Campbell, 1991)(413). Numerous studies, most of them from resource-rich settings, have identified various measures of household income, assets (e.g., home or land ownership), or wealth as consistent correlates of food insecurity (Alaimo et al., 1998; Lee \& Frongillo, 2001; Maes et al., 2010; Nelson et al., 1998; Normen et al., 2005; D. Rose, 1999a). To partition our sample by household wealth, we created a household asset index following the methodology proposed by (Filmer \& Pritchett, 2001) (see Electronic Appendix). Higher values of the asset index indicate greater relative household wealth (i.e., compared to other households in the sample). The asset index was entered into the regression models as a continuous variable.

We also adjusted for baseline employment status, educational attainment, and household size (Normen et al., 2005; D. Rose, 1999a; D. Rose, Gundersen, \& Oliveira, 1998). Employment status at baseline was measured as a binary variable equal to unity if the 
participant was unemployed. Educational attainment at baseline was measured as a binary variable equal to unity if the participant had achieved at least a secondary level of education. Household size was measured as the total number of persons in the participant's household (not including the spouse or partner) at baseline.

Our baseline adjustments for health status were more extensive than those used in previous studies (Alaimo et al., 1998; Anema et al., 2011; S. D. Weiser et al., 2009a) and included binary indicator variables for the following: self-reported history of an opportunistic infection listed in the World Health Organization (WHO) stage IV revised clinical staging of HIV/AIDS; body mass index (BMI) <18.5, indicating underweight or severely underweight; positive screening test for heavy drinking as measured by the three-item consumption subset of the Alcohol Use Disorders Identification Test (AUDIT-C) (Bush, Kivlahan, McDonell, Fihn, \& Bradley, 1998); and history of any tobacco use. Finally, we also included adjustments for baseline age, sex, marital status (either married or cohabiting), and distance to the Mbarara ISS Clinic in hours of travel time (as a proxy for rurality).

We included two additional time-varying variables in the multivariable regression models. Two binary indicator variables were used to account for seasonality, with the first equal to unity if the visit occurred during the first rainy season (February or March), and the second equal to unity if the visit occurred during the second rainy season (October or November). Duration of HIV antiretroviral treatment was measured in months.

\section{Statistical Analysis}

Food insecurity for participant $i$ at time $t$ was modeled as a linear function of social support, internalized stigma, enacted stigma, and HIV serostatus disclosure at time $t$, while adjusting for a vector of baseline demographic and clinical covariates as described previously. Parameters were estimated using least squares, with a robust estimator of variance to correct standard errors for clustering of observations within study participants over time (Froot, 1989; Rogers, 1993; Williams, 2000). Social support, HIV stigma, and serostatus disclosure were also tested for interactions with sex. To introduce a temporal gap between the exposure and outcome, we modeled food insecurity for participant $i$ at time $t+1$ as a function of timevarying social factors at time $t$, with the same demographic and clinical adjustments as detailed above.

Although we adjusted for an extensive set of demographic and clinical covariates, a potential criticism of the above models is that we may not have adjusted for all variables confounding the relationship between social factors and food insecurity. We therefore estimated a fixed effects regression model to account for the omitted variable bias resulting from any observed or unobserved, time-invariant confounders. The fixed effects models therefore contained only social support, internalized stigma, enacted stigma, HIV serostatus disclosure, the seasonal indicator variables, and duration of treatment (and excluded the fixed, time-invariant baseline demographic and clinical variables). Parameter estimates were interpreted as the association between changes in the covariates (e.g., increase in social support from one interview to the next) and changes in food insecurity.

We undertook two additional sensitivity analyses to explore the robustness of our findings. First, to explore potential nonlinearities, we applied a previously validated scoring algorithm to the HFIAS values to categorize participants as "severely food insecure" or not (i.e., food secure, mildly food insecure, or moderately food insecure) (Coates et al., 2006). Using a probit regression model to identify correlates of severe food insecurity, we obtained qualitatively similar results (see Electronic Appendix). Second, although loss to follow-up in the food security sub-study was minimal, differential dropout prior to the food security substudy may have enriched the sample for PLWHA who had greater food insecurity and low 
social support. We restricted estimation of the models to the 257 participants who were ART-naive (i.e., were simultaneously enrolling in both UARTO and the food security substudy) and excluded 199 participants who were ART-experienced (i.e., had enrolled in UARTO prior to 2007). Re-fitting the regression models on this sub-sample yielded qualitatively similar results (see Electronic Appendix).

\section{RESULTS}

The sample consisted of 456 participants followed from August 2007 to July 2010. Twenty (4.4\%) participants were lost to follow up. The median duration of follow-up was 2.1 years (interquartile range, 1.6-2.8 years). Baseline summary statistics are provided in Table 1 . The sample was predominantly female (71.4\%). Median self-reported travel time to the clinic was 40 minutes. A majority of study participants were ART-naive at the time of the baseline food insecurity sub-study visit (56.5\%). Median treatment duration among ART-experienced participants was 5.4 months. At baseline, participants reported a median social support score of 3.9 and internalized stigma score of 1.0. Ninety-three (20.4\%) participants had ever experienced enacted stigma. Slightly less than one-half (46.1\%) of participants had disclosed his or her serostatus to a neighbor.

The overall prevalence of severe food insecurity was $37.9 \%$, and this was greater among women than among men $(41.7 \%$ vs. $28.8 \% ; P=0.01)$. Frank macronutrient malnutrition appeared to be rare, as only a minority $(10.3 \%)$ were underweight or severely underweight with a BMI <18.5. HFIAS was highly variable both between participants and within (i.e., over time) participants over the study period. The overall person-quarter mean HFIAS score was 7.0, with a standard deviation between study participants of 5.4 and a standard deviation within participants of 4.0. The intra-class correlation coefficient was 0.53 , indicating that there was considerable variation between participants as well as within participants over time. Nearly one-half (41.0\%) of participants were food insecure, and $9.0 \%$ were severely food insecure, for the entire duration of follow-up.

Univariable pooled cross-sectional estimates of the association between HFIAS and demographic, clinical, and social factors are displayed in the first column of Table 2. Women had a higher mean level of food insecurity: compared to men, women had a 2.10 point greater HFIAS (95\% CI, 1.17-3.02), a 32.5\% relative increase in intensity compared to the mean HFIAS across men at baseline. Indicators of low socioeconomic status were all associated with greater food insecurity: low educational attainment, low household asset wealth, and unemployment. Serostatus disclosure, lower social support, and greater internalized stigma were also associated with greater food insecurity.

Many of these associations remained statistically significant in the multivariable regression model (second column, Table 2). Baseline household asset wealth was inversely associated with food insecurity $(\mathrm{P}<0.001)$, and its effects were also large in magnitude. Participants with the lowest asset index values had a predicted mean HFIAS of 9.99 (95\% CI, 8.8711.11), whereas participants with the highest asset index values had a predicted mean HFIAS of 1.25 (95\% CI, -0.85 to 3.34 ), an eightfold difference in food insecurity intensity. Seasonality was also observed in food insecurity.

Serostatus disclosure, social support, and HIV stigma had statistically significant associations with food insecurity. A one point greater difference in the functional social support scale was associated with a 2.02 point lower HFIAS (95\% CI, -2.79 to -1.26 ). There was nearly a twofold difference in food insecurity scores across the range of social support intensity: participants with the lowest social support scores had a predicted mean HFIAS of 11.36 (95\% CI, 9.60-13.12), whereas participants with the highest social support 
scores had a predicted mean HFIAS of 6.30 (95\% CI, 5.86-6.75). Internalized stigma also had a statistically significant association with HFIAS: the predicted mean HFIAS was 6.46 (95\% CI, 6.00-6.91) at the lowest stigma score and 9.43 (95\% CI, 8.18-10.69) at the highest score. We tested serostatus disclosure, social support, and HIV stigma for interactions by sex, but these were not statistically significant ( $P$-values ranged from 0.46 to 0.99$)$. With lagged covariates (third column, Table 2), the association of serostatus disclosure with food insecurity was no longer statistically significant. However, both social support and internalized stigma retained statistically significant associations with food insecurity.

Results from the fixed effects specification are displayed in Table 3. Because observed timeinvariant variables (e.g., sex) are collinear with the fixed effects, their associations with the outcome could not be estimated. In this specification, social support and internalized stigma retained statistically significant associations with food insecurity. Each one-point increase (i.e., from one time period to the next) in social support was associated with a 0.66 decrease $(95 \% \mathrm{CI},-1.21$ to -0.10$)$ in HFIAS. Similarly, increases in internalized and enacted stigma intensity were associated with increases in HFIAS. New HIV serostatus disclosures were not associated with changes in food insecurity, suggesting that unobserved time-invariant confounders (e.g., resilience or coping style) could explain the statistically significant associations observed in the pooled cross-sectional results. The joint statistical significance of the fixed effects was supported by a F-test $(P<0.001)$ indicating that changes in HIV stigma and social support did not fully subsume the influence of individuals on changes food insecurity.

\section{DISCUSSION}

This study demonstrated that food insecurity is common among a sample of PLWHA accessing ART in a rural sub-Saharan African setting. We also showed that lower levels of social support and greater levels of internalized HIV-related stigma are strong predictors of food insecurity in this context. These effects persisted after adjusting for household wealth, employment status, and other demographic variables previously found to be correlated with food insecurity and remained robust to alternative lagged and fixed effects specifications. Given that food insecurity is so widespread in many resource-limited settings worldwide and given its increasing recognition as an important contributor to morbidity and mortality among PLWHA, our findings have important programming and policy implications for the care of PLWHA in resource-limited settings.

Although a handful of studies have identified correlates of food insecurity in resourcelimited settings, less research has focused on food insecurity among PLWHA: our literature review identified four published studies based on data from the U.S. (Vogenthaler et al., 2010; S. D. Weiser et al., 2009a) and Canada (Anema et al., 2011; Normen et al., 2005). In these studies, the estimated prevalence of any food insecurity ranged from $34-71 \%$, comparable to the baseline prevalence estimated in our study. Our study provides a longitudinal assessment of social determinants of food insecurity among PLWHA in a resource-limited setting. In this sample of PLWHA accessing ART in rural Uganda, threequarters reported some degree of food insecurity, and more than one-third reported severe food insecurity. Since our data spanned all months of the year over a multi-year period, we were able to also observe that food insecurity varied by season. However the effects of seasonality were smaller in magnitude compared to other variables, namely, household wealth, social support, and gender. Women in our sample experienced a higher degree of food insecurity than did the men. This is consistent to what has been observed in other resource-limited settings (Anema, Vogenthaler, Frongillo, Kadiyala, \& Weiser, 2009). Due to gender inequities in intra-household resource allocation, women and female children are frequently the first household members to bear the brunt of adverse agricultural and income 
shocks (Behrman, 1988; Dercon \& Krishnan, 2000; E. Rose, 1999b). Given the central role of food security in heightening HIV risk among women (Miller, Bangsberg, Tuller, Senkungu, Kawuma, Frongillo et al., 2010; S. D. Weiser, Leiter, Bangsberg, Butler, Percyde Korte, Hlanze et al., 2007) and worsening clinical outcomes among those already infected (Anema et al., 2009; S. D. Weiser et al., 2011b), this may contribute to widening the gender inequities observed in the distribution of HIV/AIDS harms worldwide.

This study is additionally notable for its focus on social determinants of food insecurity. We found that food insecurity was related to internalized HIV-related stigma and inversely related to social support. These findings are consistent with a recently published conceptual model of the bidirectional linkages between food insecurity and HIV/AIDS (S. D. Weiser et al., 2011b). In this conceptual model, food insecurity is not only worsened by physical factors such as HIV-related illness leading to job loss and asset depletion, but also by social factors such as HIV-related stigma leading to reduced ability to draw on social networks for instrumental assistance. In our study, the estimated effect of internalized stigma was more robust than that of enacted stigma across the different specifications. To the extent that the effects of internalized stigma can be reliably disentangled from and compared to the effects of enacted stigma, this finding is less consistent with a hypothesis of active discrimination that prevents access to food and more consistent with a hypothesis of stigma-induced social withdrawal that prevents PLWHA from accessing instrumental help to secure food. Similar patterns have been observed in other settings, where social support and HIV-related stigma have been identified as critical determinants of ART adherence (Bangsberg \& Deeks, 2010; Crane, Kawuma, Oyugi, Byakika, Moss, Bourgois et al., 2006; Tsai \& Bangsberg, 2011; Ware et al., 2009).

There is a large literature on the relationship between social capital, social support, and health status (Berkman, 1984; Berkman, Glass, Brissette, \& Seeman, 2000; Berkman \& Syme, 1979; Broadhead et al., 1983), but food insecurity has been less well studied. Data from the U.S. have linked measures of social isolation, social support, and/or social capital to related constructs, including food insecurity (Dean \& Sharkey, 2011; Martin, Rogers, Cook, \& Joseph, 2004) and nutritional risk (Locher, Ritchie, Roth, Baker, Bodner, \& Allman, 2005). Notably, clinical data were unavailable in all three of these U.S.-based studies. Martin et al. (2004) hypothesized that households with greater social capital can more easily obtain food from neighbors or borrow a neighbor's car to get to the supermarket. This is consistent with observations made by Kawachi (1999) and others (Kawachi, Kim, Coutts, \& Subramanian, 2004; Putnam, 2004; Szreter \& Woolcock, 2004) that the salubrious effects of social capital likely operate through access to various forms of instrumental social support.

Interpretation of our findings is subject to several limitations. First, our parameter estimates have an associational, not a causal, interpretation. Given that lack of food may prompt persons to procure food in socially unacceptable ways (Radimer, Olson, \& Campbell, 1990), the observed association between social support and food insecurity could instead be explained by food insecurity resulting in adverse social sequelae that erodes social support. In the lagged specification, which we used to strengthen our confidence in the directionality of our findings, the effects of disclosure and HIV stigma were not statistically significant. This suggested either that they are not causally related to food insecurity or that their effects on food insecurity are more immediate than would be captured with a three-month lag. Second, HIV stigma and social support, as well as food insecurity, were self-reported and consisted largely of the study participant's observations and perceptions. A study participant's personality and temperament may affect the perception of social support and may also affect the ability to effectively procure food or cope with the uncertain availability of food. However, social support retained a statistically significant association with food 
insecurity even after adjusting for all observed and unobserved time-invariant confounders (such as personality) using fixed effects regression, thereby ruling out the possibility of confounding by personality or temperament. Third, our findings may not be generalizable to other contexts. Related to this, the sample was comprised of mostly women. The ISS Clinic is a prototypical clinic funded by the U.S. President's Emergency Plan for AIDS Relief to provide HIV treatment and care services (Geng et al., 2010), and it is well known that in resource-limited settings most PLWHA accessing treatment are women (Braitstein, Boulle, Nash, Brinkhof, Dabis, Laurent et al., 2008; Muula, Ngulube, Siziya, Makupe, Umar, Prozesky et al., 2007). HIV testing among women attending antenatal care has been reported as an important entry point for women into HIV treatment and may be an important factor in explaining these trends (Stringer, Stringer, Cliver, Goldenberg, \& Goepfert, 2001). We may have had limited power to detect differences in food insecurity between men and women, but the data suggest that the two subgroups are statistically different in this respect. Finally, the stigma attached to HIV in Uganda is not dissimilar to the experience of PLWHA in other sub-Saharan African settings (Genberg et al., 2009; Genberg, Kawichai, Chingono, Sendah, Chariyalertsak, Konda et al., 2008; S. C. Kalichman, Simbayi, Jooste, Toefy, Cain, Cherry et al., 2005). These factors would tend to support the generalizability of our findings.

In summary, we found that food insecurity is highly prevalent among ART-treated PLWHA in our study area in rural Uganda, especially women, and that it is seasonal and closely linked to HIV-related stigma and social support. The WHO, UNAIDS, and WFP have recommended incorporating food and nutrition interventions into HIV/AIDS programming (UNAIDS, 2008; World Food Programme, 2003), but more research is needed to guide the targeting of such interventions (Tirivayi \& Groot, 2011). Our study provides a quantitative assessment of determinants of food insecurity among PLWHA in a resource-limited setting and suggests several demographic, seasonal, and social points of intervention. Specifically, structural interventions are needed to address unequal gender relations (Zierler \& Krieger, 1997), food insecurity (S. D. Weiser et al., 2010), social capital (Feigenberg, Field, \& Pande, 2010; Pronyk, Harpham, Busza, Phetla, Morison, Hargreaves et al., 2008; Sanyal, 2009), and/or HIV-related stigma (Ehiri, Anyanwu, Donath, Kanu, \& Jolly, 2005) in the context of ongoing HIV treatment. For example, microcredit and/or micro-irrigation interventions developed for PLWHA may address some of these levers simultaneously. These strategies have been explored (Ashburn, Kerrigan, \& Sweat, 2008; Pandit, Sirotin, Tittle, Onjolo, Bukusi, \& Cohen, 2010) and may prove, with further randomized study, to be promising interventions that can interrupt the cycle of food insecurity and HIV/AIDS.

\section{Supplementary Material}

Refer to Web version on PubMed Central for supplementary material.

\section{Acknowledgments}

We thank the Uganda AIDS Rural Treatment Outcomes study participants who made this study possible by sharing their experiences; Annet Kawuma and Annet Kembabazi for providing study coordination and support; and Doreen Akello, Marcy Mutumba, Christine Ngabirano, Ruth Ssentongo, and Florence Turyashemererwa for research assistance. Edward Frongillo, Jessica Haberer, Peter W. Hunt, and F.B. Nozmo Mukiibi provided invaluable input on study design and implementation. While these individuals are acknowledged for their assistance, no endorsement of manuscript contents or conclusions should be inferred. The study was funded by U.S. National Institutes of Health K23 MH-79713 and MH-79713-03S1 (PI: Weiser), R01 MH-054907 (PI: Bangsberg), P30 AI27763 (UCSF-Gladstone Institute Center for AIDS Research), and the Tim and Jane Meyer Family Foundation. The authors acknowledge the following additional sources of support: Robert Wood Johnson Foundation Health \& Society Scholars Program (Tsai), K24 MH-087227 (Bangsberg), and the Burke Family Foundation (Weiser). 


\section{References}

Abadia-Barrero CE, Castro A. Experiences of stigma and access to HAART in children and adolescents living with HIV/AIDS in Brazil. Soc Sci Med. 2006; 62(5):1219-1228. [PubMed: 16099573]

Alaimo K, Briefel RR, Frongillo EA Jr, Olson CM. Food insufficiency exists in the United States: results from the third National Health and Nutrition Examination Survey (NHANES III). Am J Public Health. 1998; 88(3):419-426. [PubMed: 9518974]

Anderson SA. Core indicators of nutritional state for difficult-to-sample populations. J Nutr. 1990; 120(11):1559-1600. [PubMed: 2243305]

Anema A, Vogenthaler N, Frongillo EA, Kadiyala S, Weiser SD. Food insecurity and HIV/AIDS: current knowledge, gaps, and research priorities. Curr HIV/AIDS Rep. 2009; 6(4):224-231. [PubMed: 19849966]

Anema A, Weiser SD, Fernandes KA, Ding E, Brandson EK, Palmer A, et al. High prevalence of food insecurity among HIV-infected individuals receiving HAART in a resource-rich setting. AIDS Care. 2011; 23(2):221-230. [PubMed: 21259135]

Antelman G, Smith Fawzi MC, Kaaya S, Mbwambo J, Msamanga GI, Hunter DJ, et al. Predictors of HIV-1 serostatus disclosure: a prospective study among HIV-infected pregnant women in Dar es Salaam, Tanzania. AIDS. 2001; 15(14):1865-1874. [PubMed: 11579250]

Ashburn K, Kerrigan D, Sweat M. Micro-credit, women's groups, control of own money: HIV-related negotiation among partnered Dominican women. AIDS Behav. 2008; 12(3):396-403. [PubMed: 17602292]

Bangsberg DR, Deeks SG. Spending more to save more: interventions to promote adherence. Ann Intern Med. 2010; 152(1):54-56. [PubMed: 20048272]

Behrman J. Intrahousehold allocation of nutrients in rural India: Are boys favored? Do parents exhibit inequality aversion? Oxford Econ Papers. 1988; 40(1):32-54.

Berkman LF. Assessing the physical health effects of social networks and social support. Annu Rev Public Health. 1984; 5:413-432. [PubMed: 6372817]

Berkman LF, Glass T, Brissette I, Seeman TE. From social integration to health: Durkheim in the new millennium. Soc Sci Med. 2000; 51(6):843-857. [PubMed: 10972429]

Berkman LF, Syme SL. Social networks, host resistance, and mortality: a nine-year follow-up study of Alameda County residents. Am J Epidemiol. 1979; 109(2):186-204. [PubMed: 425958]

Braitstein P, Boulle A, Nash D, Brinkhof MW, Dabis F, Laurent C, et al. Gender and the use of antiretroviral treatment in resource-constrained settings: findings from a multicenter collaboration. J Womens Health (Larchmt). 2008; 17(1):47-55. [PubMed: 18240981]

Broadhead WE, Gehlbach SH, de Gruy FV, Kaplan BH. The Duke-UNC Functional Social Support Questionnaire. Measurement of social support in family medicine patients. Med Care. 1988; 26(7): 709-723. [PubMed: 3393031]

Broadhead WE, Kaplan BH, James SA, Wagner EH, Schoenbach VJ, Grimson R, et al. The epidemiologic evidence for a relationship between social support and health. Am J Epidemiol. 1983; 117(5):521-537. [PubMed: 6342368]

Bukusuba J, Kikafunda JK, Whitehead RG. Food security status in households of people living with HIV/AIDS (PLWHA) in a Ugandan urban setting. Br J Nutr. 2007; 98(1):211-217. [PubMed: 17381879]

Bush K, Kivlahan DR, McDonell MB, Fihn SD, Bradley KA. The AUDIT alcohol consumption questions (AUDIT-C): an effective brief screening test for problem drinking. Ambulatory Care Quality Improvement Project (ACQUIP). Alcohol Use Disorders Identification Test. Arch Intern Med. 1998; 158(16):1789-1795. [PubMed: 9738608]

Campbell CC. Food insecurity: a nutritional outcome or a predictor variable? J Nutr. 1991; 121(3): 408-415. [PubMed: 2002411]

Carter MR, Maluccio JA. Social capital and coping with economic shocks: an analysis of stunting of South African children. World Dev. 2003; 31(7):1147-1163.

Chapoto A, Jayne TS. Impact of AIDS-related mortality on farm household welfare in Zambia. Econ Dev Cult Change. 2008; 56(2):327-374. 
Coates, J.; Swindale, A.; Bilinsky, P. Household Food Insecurity Access Scale (HFIAS) for measurement of food access: indicator guide. Washington, D.C: Food and Nutrition Technical Assistance Project, Academy for Educational Development; 2006.

Crane JT, Kawuma A, Oyugi JH, Byakika JT, Moss A, Bourgois P, et al. The price of adherence: qualitative findings from HIV positive individuals purchasing fixed-dose combination generic HIV antiretroviral therapy in Kampala, Uganda. AIDS Behav. 2006; 10(4):437-442. [PubMed: 16636892]

Daniel H. We are all people living with AIDS: myths and realities of AIDS in Brazil. Int J Health Serv. 1991; 21(3):539-551. [PubMed: 1917212]

Danziger R. The social impact of HIV/AIDS in developing countries. Soc Sci Med. 1994; 39(7):905917. [PubMed: 7992124]

de Weerdt J, Dercon S. Risk-sharing networks and insurance against illness. J Dev Econ. 2006; 81(2): 337-356.

Dean WR, Sharkey JR. Food insecurity, social capital and perceived personal disparity in a predominantly rural region of Texas: An individual-level analysis. Soc Sci Med. 2011; 72(9): 1454-1462. [PubMed: 21497429]

Dercon S, Krishnan P. In sickness and in health: risk sharing within households in rural Ethiopia. J Polit Econ. 2000; 108(4):688-727.

Ehiri JE, Anyanwu EC, Donath E, Kanu I, Jolly PE. AIDS-related stigma in sub-Saharan Africa: its contexts and potential intervention strategies. AIDS Public Policy J. 2005; 20(1-2):25-39. [PubMed: 17260567]

FAO. The state of food insecurity in the world: addressing food insecurity in protracted crises. Rome: Food and Agriculture Organization of the United Nations; 2010.

Feigenberg, B.; Field, EM.; Pande, R. National Bureau of Economic Research Working Paper No. 16018. Cambridge: National Bureau of Economic Research; 2010. Building social capital through microfinance.

Filmer D, Pritchett LH. Estimating wealth effects without expenditure data -- or tears: an application to educational enrollments in states of India. Demography. 2001; 38(1):115-132. [PubMed: 11227840]

Froot KA. Consistent covariance matrix estimation with cross-sectional dependence and heteroskedasticity in financial data. J Fin Quant Analysis. 1989; 24(3):333-355.

Garasky S, Morton LW, Greder KA. The effects of the local food environment and social support on rural food insecurity. J Hunger Env Nutr. 2006; 1(1):83-103.

Genberg BL, Hlavka Z, Konda KA, Maman S, Chariyalertsak S, Chingono A, et al. A comparison of HIV/AIDS-related stigma in four countries: negative attitudes and perceived acts of discrimination towards people living with HIV/AIDS. Soc Sci Med. 2009; 68(12):2279-2287. [PubMed: 19427086]

Genberg BL, Kawichai S, Chingono A, Sendah M, Chariyalertsak S, Konda KA, et al. Assessing HIV/ AIDS stigma and discrimination in developing countries. AIDS Behav. 2008; 12(5):772-780. [PubMed: 18080830]

Geng EH, Bwana MB, Kabakyenga J, Muyindike W, Emenyonu NI, Musinguzi N, et al. Diminishing availability of publicly funded slots for antiretroviral initiation among HIV-infected ART-eligible patients in Uganda. PLoS One. 2010; 5(11):e14098. [PubMed: 21124842]

Hadley C, Mulder MB, Fitzherbert E. Seasonal food insecurity and perceived social support in rural Tanzania. Public Health Nutr. 2007; 10(6):544-551. [PubMed: 17381917]

Heflin CM, Corcoran ME, Siefert KA. Work trajectories, income changes, and food insufficiency in a Michigan welfare population. Soc Serv Rev. 2007; 81(1):3-25.

Heumann, N. Unpublished PhD dissertation. Gießen: Fachbereiches Agrarwissenschaften, Ökotrophologie und Umweltmanagement, Justus-Liebig-Universität; 2010. Soziale netzwerke südafrikanischer farmarbeiter im kontext von nahrungs und existenzsicherheit: ein methoden-mix mit gender aspekten.

Hosegood V, Preston-Whyte E, Busza J, Moitse S, Timaeus IM. Revealing the full extent of households' experiences of HIV and AIDS in rural South Africa. Soc Sci Med. 2007; 65(6):12491259. [PubMed: 17570572] 
Kalichman SC, Simbayi LC, Cloete A, Mthembu PP, Mkhonta RN, Ginindza T. Measuring AIDS stigmas in people living with HIV/AIDS: the Internalized AIDS-Related Stigma Scale. AIDS Care. 2009; 21(1):87-93. [PubMed: 19085224]

Kalichman SC, Simbayi LC, Jooste S, Toefy Y, Cain D, Cherry C, et al. Development of a brief scale to measure AIDS-related stigma in South Africa. AIDS Behav. 2005; 9(2):135-143. [PubMed: 15933833]

Kaschula S. Using people to cope with hunger: social networks and food transfers amongst HIV/AIDS afflicted households in KwaZulu-Natal, South Africa. AIDS Behav. 2011 [Epub ahead of print Aug 6].

Kawachi I. Social capital and community effects on population and individual health. Ann N Y Acad Sci. 1999; 896:120-130. [PubMed: 10681893]

Kawachi I, Kim D, Coutts A, Subramanian SV. Commentary: Reconciling the three accounts of social capital. Int J Epidemiol. 2004; 33(4):682-690. discussion 700-684. [PubMed: 15282222]

la Ferrara E. Kin groups and reciprocity: a model of credit transactions in Ghana. Am Econ Rev. 2003; 93(5):1730-1751.

Lee JS, Frongillo EA Jr. Factors associated with food insecurity among U.S. elderly persons: importance of functional impairments. J Gerontol B Psychol Sci Soc Sci. 2001; 56(2):S94-99. [PubMed: 11245369]

Locher JL, Ritchie CS, Roth DL, Baker PS, Bodner EV, Allman RM. Social isolation, support, and capital and nutritional risk in an older sample: ethnic and gender differences. Soc Sci Med. 2005; 60(4):747-761. [PubMed: 15571893]

Maes KC, Hadley C, Tesfaye F, Shifferaw S. Food insecurity and mental health: Surprising trends among community health volunteers in Addis Ababa, Ethiopia during the 2008 food crisis. Soc Sci Med. 2010; 70(9):1450-1457. [PubMed: 20189698]

Mak WW, Cheung RY, Law RW, Woo J, Li PC, Chung RW. Examining attribution model of selfstigma on social support and psychological well-being among people with HIV+/AIDS. Soc Sci Med. 2007; 64(8):1549-1559. [PubMed: 17223239]

Martin KS, Rogers BL, Cook JT, Joseph HM. Social capital is associated with decreased risk of hunger. Soc Sci Med. 2004; 58(12):2645-2654. [PubMed: 15081212]

Masanjala W. The poverty-HIV/AIDS nexus in Africa: a livelihood approach. Soc Sci Med. 2007; 64(5):1032-1041. [PubMed: 17126972]

McGrath JW, Ankrah EM, Schumann DA, Nkumbi S, Lubega M. AIDS and the urban family: its impact in Kampala, Uganda. AIDS Care. 1993; 5(1):55-70. [PubMed: 8461362]

Miller CL, Bangsberg DR, Tuller DM, Senkungu J, Kawuma A, Frongillo EA, et al. Food insecurity and sexual risk in an HIV endemic community in Uganda. AIDS Behav. 2010 Epub ahead of print Apr 20.

Muula AS, Ngulube TJ, Siziya S, Makupe CM, Umar E, Prozesky HW, et al. Gender distribution of adult patients on highly active antiretroviral therapy (HAART) in Southern Africa: a systematic review. BMC Public Health. 2007; 7:63. [PubMed: 17459154]

Muyinda H, Seeley J, Pickering H, Barton T. Social aspects of AIDS-related stigma in rural Uganda. Health Place. 1997; 3(3):143-147. [PubMed: 10670965]

Nelson K, Brown ME, Lurie N. Hunger in an adult patient population. JAMA. 1998; 279(15):12111214. [PubMed: 9555762]

Normen L, Chan K, Braitstein P, Anema A, Bondy G, Montaner JS, et al. Food insecurity and hunger are prevalent among HIV-positive individuals in British Columbia, Canada. J Nutr. 2005; 135(4): 820-825. [PubMed: 15795441]

Nyblade, L.; MacQuarrie, K. Current knowledge about quantifying stigma in developing countries. Washington, D.C: U.S. Agency for International Development; 2006. Can we measure HIV/AIDSrelated stigma and discrimination?.

Okoror TA, Airhihenbuwa CO, Zungu M, Makofani D, Brown DC, Iwelunmor J. "My mother told me I must not cook anymore"--food, culture, and the context of HIV- and AIDS-related stigma in three communities in South Africa. Int Q Community Health Educ. 2007; 28(3):201-213. [PubMed: 19095587] 
Pandit JA, Sirotin N, Tittle R, Onjolo E, Bukusi EA, Cohen CR. Shamba Maisha: a pilot study assessing impacts of a micro-irrigation intervention on the health and economic wellbeing of HIV patients. BMC Pub Health. 2010; 10:245. [PubMed: 20459841]

Pronyk PM, Harpham T, Busza J, Phetla G, Morison LA, Hargreaves JR, et al. Can social capital be intentionally generated? a randomized trial from rural South Africa. Soc Sci Med. 2008; 67(10): 1559-1570. [PubMed: 18771833]

Putnam RD. Commentary: "Health by association": some comments. Int J Epidemiol. 2004; 33(4): 667-671. discussion 700-664. [PubMed: 15282226]

Radimer KL, Olson CM, Campbell CC. Development of indicators to assess hunger. J Nutr. 1990; 120(Suppl 11):1544-1548. [PubMed: 2243303]

Radimer KL, Olson CM, Greene JC, Campbell CC, Habicht JP. Understanding hunger and developing indicators to assess it in women and children. J Nutr Educ. 1992; 24(Suppl 1):36S-45S.

Rogers WH. Regression standard errors in clustered samples. Stata Tech Bull. 1993; 13:19-23.

Rose D. Economic determinants and dietary consequences of food insecurity in the United States. J Nutr. 1999a; 129(2S Suppl):517S-520S. [PubMed: 10064321]

Rose, D.; Gundersen, C.; Oliveira, V. Technical Bulletin No. 1869. Washington, D.C: Food and Rural Economics Division, Economic Research Service, U.S. Department of Agriculture; 1998. Socioeconomic determinants of food insecurity in the United States: evidence from the SIPP and CSFII datasets.

Rose E. Consumption smoothing and excess female mortality in rural India. Rev Econ Stat. 1999b; 81(1):41-49.

Sanyal P. From credit to collective action: the role of microfinance in promoting women's social capital and normative influence. Am Sociol Rev. 2009; 74(4):529-550.

Simbayi LC, Kalichman S, Strebel A, Cloete A, Henda N, Mqeketo A. Internalized stigma, discrimination, and depression among men and women living with HIV/AIDS in Cape Town, South Africa. Soc Sci Med. 2007; 64(9):1823-1831. [PubMed: 17337318]

Steward WT, Herek GM, Ramakrishna J, Bharat S, Chandy S, Wrubel J, et al. HIV-related stigma: adapting a theoretical framework for use in India. Soc Sci Med. 2008; 67(8):1225-1235. [PubMed: 18599171]

Stringer EM, Stringer JS, Cliver SP, Goldenberg RL, Goepfert AR. Evaluation of a new testing policy for human immunodeficiency virus to improve screening rates. Obstet Gynecol. 2001; 98(6): 1104-1108. [PubMed: 11755561]

Szreter S, Woolcock M. Health by association? Social capital, social theory, and the political economy of public health. Int J Epidemiol. 2004; 33(4):650-667. [PubMed: 15282219]

Tirivayi N, Groot W. Health and welfare effects of integrating AIDS treatment with food assistance in resource constrained settings: a systematic review of theory and evidence. Soc Sci Med. 2011; 73(5):685-692. [PubMed: 21824702]

Tsai AC, Bangsberg DR. The importance of social ties in sustaining medication adherence in resourcelimited settings. J Gen Intern Med. 2011 [Epub ahead of print Aug 31].

Uganda Ministry of Health. Uganda HIV/AIDS sero-behavioural survey, 2004-2005. Kampala, Uganda: Uganda Ministry of Health and ORC/Macro; 2006.

UNAIDS. HIV, food security, and nutrition. Geneva: Joint United Nations Programme on HIV/AIDS; 2008.

UNAIDS. Global report: UNAIDS report on the global AIDS epidemic. Geneva: Joint United Nations Programme on HIV/AIDS; 2010.

Vogenthaler NS, Hadley C, Lewis SJ, Rodriguez AE, Metsch LR, del Rio C. Food insufficiency among HIV-infected crack-cocaine users in Atlanta and Miami. Public Health Nutr. 2010; 13(9): 1478-1484. [PubMed: 20074395]

Ware NC, Idoko J, Kaaya S, Biraro IA, Wyatt MA, Agbaji O, et al. Explaining adherence success in sub-Saharan Africa: an ethnographic study. PLoS Med. 2009; 6(1):e11. [PubMed: 19175285]

Weiser S, Wolfe W, Bangsberg D, Thior I, Gilbert P, Makhema J, et al. Barriers to antiretroviral adherence for patients living with HIV infection and AIDS in Botswana. J Acquir Immune Defic Syndr. 2003; 34(3):281-288. [PubMed: 14600572] 
Weiser SD, Bangsberg DR, Kegeles S, Ragland K, Kushel MB, Frongillo EA. Food insecurity among homeless and marginally housed individuals living with HIV/AIDS in San Francisco. AIDS Behav. 2009a; 13(5):841-848. [PubMed: 19644748]

Weiser SD, Fernandes KA, Brandson EK, Lima VD, Anema A, Bangsberg DR, et al. The association between food insecurity and mortality among HIV-infected individuals on HAART. J Acquir Immune Defic Syndr. 2009b; 52(3):342-349. [PubMed: 19675463]

Weiser SD, Frongillo EA, Ragland K, Hogg RS, Riley ED, Bangsberg DR. Food insecurity is associated with incomplete HIV RNA suppression among homeless and marginally housed HIVinfected individuals in San Francisco. J Gen Intern Med. 2009c; 24(1):14-20. [PubMed: 18953617]

Weiser SD, Leiter K, Bangsberg DR, Butler LM, Percy-de Korte F, Hlanze Z, et al. Food insufficiency is associated with high-risk sexual behavior among women in Botswana and Swaziland. PLoS Med. 2007; 4(10):1589-1597. discussion 1598. [PubMed: 17958460]

Weiser SD, Tsai AC, Gupta R, Frongillo EA, Kawuma A, Senkungu JK, et al. Food insecurity is associated with morbidity and patterns of healthcare utilization among HIV-infected individuals in rural Uganda. AIDS. 2011a [Epub ahead of print Sept 6].

Weiser SD, Tuller DM, Frongillo EA, Senkungu J, Mukiibi N, Bangsberg DR. Food insecurity as a barrier to sustained antiretroviral therapy adherence in Uganda. PLoS One. 2010; 5(4):e10340. [PubMed: 20442769]

Weiser SD, Young SL, Cohen CR, Kushel MB, Tsai AC, Tien PC, et al. Conceptual framework for understanding the bidirectional links between food insecurity and HIV/AIDS. Am J Clin Nutr. $2011 \mathrm{~b}$ forthcoming.

Williams RL. A note on robust variance estimation for cluster-correlated data. Biometrics. 2000; 56(2):645-646. [PubMed: 10877330]

Wolfe WR, Weiser SD, Bangsberg DR, Thior I, Makhema JM, Dickinson DB, et al. Effects of HIVrelated stigma among an early sample of patients receiving antiretroviral therapy in Botswana. AIDS Care. 2006; 18(8):931-933. [PubMed: 17012082]

Wolfe WR, Weiser SD, Leiter K, Steward WT, Percy-de Korte F, Phaladze N, et al. The impact of universal access to antiretroviral therapy on HIV stigma in Botswana. Am J Public Health. 2008; 98(10):1865-1871. [PubMed: 18703447]

World Food Programme. Programming in the era of AIDS: WFP's response to HIV/AIDS. Rome: World Food Programme of the United Nations; 2003.

Yamano T, Jayne TS. Measuring the impact of working-age adult mortality on small-scale farm households in Kenya. World Dev. 2004; 32(1):91-119.

Zierler S, Krieger N. Reframing women's risk: social inequalities and HIV infection. Annu Rev Public Health. 1997; 18:401-436. [PubMed: 9143725] 


\section{RESEARCH HIGHLIGHTS}

Adequate food is critical to health for PLWHA, but little research has examined determinants of food insecurity among PLWHA in resource-limited settings

We found that social support and HIV-related stigma were robustly associated with food insecurity

Using longitudinal data, we found these associations to be robust to multiple specifications, including lagged covariates and fixed effects

Interventions to reduce HIV-related stigma \& improve social support for PLWHA may help to interrupt the cycle of food insecurity and HIV 


\section{TABLE 1}

Summary statistics at baseline $(\mathrm{N}=456)$

\begin{tabular}{|c|c|c|}
\hline Variable name & $\begin{array}{l}\text { Median (inter- quartile range) } \\
\text { or number (percent) }\end{array}$ & $\begin{array}{r}\text { Number of missing } \\
\text { observations }\end{array}$ \\
\hline Household Food Insecurity Access Scale (HFIAS), total score & $7(1-13)$ & 6 \\
\hline HFIAS category & & 4 \\
\hline Food secure & $112(24.6 \%)$ & \\
\hline Mildly food insecure & $32(7.0 \%)$ & \\
\hline Moderately food insecure & $135(29.6 \%)$ & \\
\hline Severely food insecure & $173(37.9 \%)$ & \\
\hline Age (years) & $35(29-40)$ & 6 \\
\hline Female & $324(71.1 \%)$ & 0 \\
\hline Married & $204(44.7 \%)$ & 0 \\
\hline Household size & $3(1-5)$ & 2 \\
\hline Achieved secondary education & $109(23.9 \%)$ & 0 \\
\hline Filmer-Pritchett asset index & $-0.3(-1.5$ to 1.2$)$ & 26 \\
\hline Unemployed & $133(29.2 \%)$ & 7 \\
\hline Distance to Mbarara ISS Clinic (hours) & $0.7(0.5-1)$ & 1 \\
\hline Positive screening test for heavy drinking & $35(7.7 \%)$ & 22 \\
\hline Any history of tobacco use & $104(22.8 \%)$ & 16 \\
\hline Season of baseline visit & & 0 \\
\hline Dry season & $183(40.1 \%)$ & \\
\hline First planting season (February or March) & $53(11.4 \%)$ & \\
\hline Second planting season (October or November) & $221(48.5 \%)$ & \\
\hline ART-naive & $257(56.4 \%)$ & 0 \\
\hline Duration of antiretroviral treatment, among ART-experienced (months) & $5.4(0-11.9)$ & 0 \\
\hline Self-reported history of opportunistic infection & $142(31.1 \%)$ & 6 \\
\hline BMI category & & 23 \\
\hline Severely underweight $(<16.5)$ & $8(1.8 \%)$ & \\
\hline Underweight $(16.5$ to $<18.5)$ & $39(8.6 \%)$ & \\
\hline Normal $(18.5$ to $<25)$ & $302(66.2 \%)$ & \\
\hline Overweight $(25$ to $<30)$ & $69(15.1 \%)$ & \\
\hline Obese ( 30 or greater) & $15(3.3 \%)$ & \\
\hline Disclosed HIV serostatus to a neighbor & $210(46.1 \%)$ & 14 \\
\hline Functional Social Support Scale & $3.9(3.5-4.0)$ & 2 \\
\hline Internalized AIDS-Related Stigma Scale & $1.0(0-2)$ & 6 \\
\hline Enacted stigma scale & $0(0-0)$ & 5 \\
\hline Any history of enacted stigma & $93(20.4 \%)$ & 13 \\
\hline
\end{tabular}




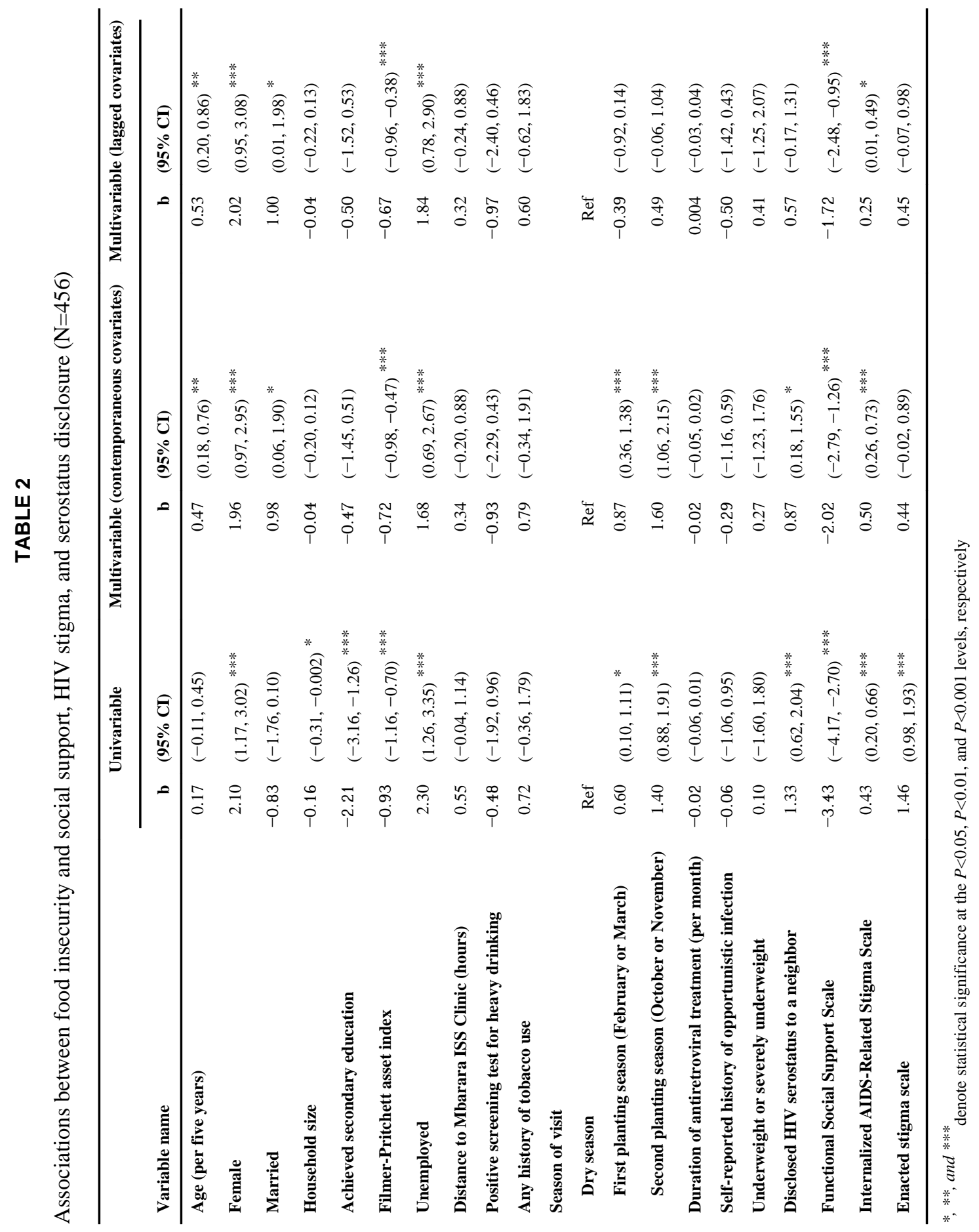


TABLE 3

Fixed-effects estimates of the associations between change in food insecurity and changes in social support, HIV stigma, and serostatus disclosure $(\mathrm{N}=456)$

\begin{tabular}{lrl}
\hline Variable name & b & $(\mathbf{9 5 \%}$ CI $)$ \\
\hline Season of visit & Ref & \\
$\quad$ Dry season & 0.57 & $(0.15,1.00)^{* *}$ \\
$\quad$ First planting season (February or March) & 1.31 & $(0.84,1.77)^{* * *}$ \\
$\quad$ Second planting season (October or November) & -0.02 & $(-0.06,0.006)$ \\
Duration of antiretroviral treatment (per month) & -0.33 & $(-0.84,0.19)$ \\
Disclosed HIV serostatus to a neighbor & -0.66 & $(-1.21,-0.10)$ \\
Functional Social Support Scale & 0.50 & $(0.32,0.69)$ \\
Internalized AIDS-Related Stigma Scale & 0.43 & $(0.05,0.80)$ \\
\hline Enacted stigma scale & & \\
\hline
\end{tabular}

*,**, and $* * *$ denote statistical significance at the $P<0.05, P<0.01$, and $P<0.001$ levels, respectively 